\title{
Desenvolvimentismo, industrialização e ensino superior em Chapecó: bases para a criação de um movimento estudantil
}

\section{Development, Industrialization and Higher Education in Chapecó: bases for the creation of a student movement}

\author{
Vinicius de Almeida Peres ${ }^{1}$ \\ Monica Hass ${ }^{2}$
}

\begin{abstract}
Resumo: $\mathrm{O}$ artigo tem por objetivos apresentar a ligação entre a expansão/interiorização do ensino e o projeto desenvolvimentista no contexto do governo civil-militar, problematizar os interesses que influenciaram a implementação do ensino superior no município de Chapecó e apontar a formação de um movimento estudantil no CES/Fundeste junto a algumas de suas demandas e lutas. A análise terá como foco as décadas de 1960 e 1970, utilizando-se pesquisa bibliográfica e documental. Constata-se que a educação foi uma área estratégica para o projeto desenvolvimentista, agindo simultaneamente em duas frentes: uma em favor do capital e outra que busca reduzir problemas sociais. Por sua vez, o movimento estudantil do CES/Fundeste, mesmo em estruturação a partir de 1973, pôde gerar benefícios para o ensino superior e para o município.
\end{abstract}

Palavras-chave: Desenvolvimentismo. CES/Fundeste de Chapecó. Movimento Estudantil.

\begin{abstract}
The article aims to present the link between the expansion / internalization of teaching and the developmentalist project in the context of civil-military government, to problematize the interests that influenced the implementation of higher education in the municipality of Chapecó and to point out the formation of a student movement in the CES/Fundeste along with some of their demands and struggles. The analysis will focus on the 1960s and 1970s, using bibliographical and documentary research. It was observed that education was a strategic area for the developmentalist project, acting simultaneously on two fronts: one in favor of capital and another that seeks to reduce social problems. In turn, the CES/Fundeste student movement, even in structuring after 1973, could generate benefits for higher education and for the municipality.
\end{abstract}

Keywords: Developmentalism. CES/Fundeste in Chapecó. Student Movement.

\section{Introdução}

O movimento estudantil pode ser identificado tanto como uma forma de ativismo no campo da educação quanto como um movimento social organizado e composto por jovens que se enquadram na categoria de estudantes. No Brasil, ele é reconhecido por lutas voltadas a questões educacionais, as quais têm como reivindicações qualidade no ensino, qualidade de infraestrutura para o setor educacional, variadas formas de inclusão, auxílio a estudantes carentes, universalidade do acesso à educação, redução de valores de mensalidades (ou mesmo sua gratuidade), entre outras.

\footnotetext{
${ }^{1}$ Mestrando em História pela Universidade Federal da Fronteira Sul (UFFS), Campus Chapecó-SC. E-mail: peres.vinicius@hotmail.com

${ }^{2}$ Doutora em Sociologia Política pela Universidade Federal de Santa Catarina (UFSC). Professora na Universidade Federal da Fronteira Sul (UFFS), Campus Chapecó-SC. E-mail: monica@uffs.edu.br
} 
Apesar disso, a história do movimento estudantil nos mostra que, por vezes, os estudantes, críticos das estruturas e conjunturas do momento em que viviam, também desenvolveram atuações para além dos muros e dos domínios das instituições de ensino. Em diferentes momentos, eles adentraram pautas sociais, econômicas e políticas que não estavam diretamente ligadas a questões educacionais, mas que ressoavam na sociedade, assim dialogando e/ou se associando a outros grupos sociais, ou mesmo formulando posicionamentos próprios.

Durante o século XX, além da estruturação em uma rede de entidades, o movimento estudantil viveu seu auge, mas também declinou tanto em sua capacidade de mobilização como em seus quadros de participação. Nesse período, talvez o marco mais importante de suas ações tenha sido a resistência na oposição ao governo ditatorial entre 1964 e 1985.

No Brasil, a ligação das grandes entidades estudantis predominantemente com universidades públicas localizadas em capitais e grandes centros urbanos fez com que as ações e lutas dos estudantes oriundos dessas instituições recebessem destaque na historiografia e marcassem a memória coletiva sobre o movimento estudantil (LIMA, 2011). Contudo, os projetos de expansão e interiorização do ensino colocados em prática durante a ditadura civilmilitar, associados aos interesses empresariais e tecnicistas, levaram o movimento estudantil a se expandir e a diversificar ainda mais os interesses e necessidades que permeavam as dissidências internas que disputavam a liderança do movimento (SANTANA, 2007).

Por sua vez, a penetração do movimento em instituições privadas e comunitárias, as quais se proliferaram nos pequenos municípios e regiões interioranas como uma forma de desdobramento dos projetos em prol da expansão e interiorização do ensino e das tentativas de reforma universitária, trouxe novas características ao movimento estudantil. Em alguns casos, houve a formação de blocos alinhados ou oposicionistas às pautas das representações estaduais e nacionais; em outros, a busca pela gênese de movimentos que se pretendiam novos e autônomos (LIMA, 2011).

De toda forma, a história do movimento estudantil permanece sendo escrita privilegiando uma visão que fortalece a crença em um movimento coeso em torno da União Nacional dos Estudantes (UNE) - ainda que se reconheça a existência de divergências - e característico do ensino público dos grandes centros urbanos (LIMA, 2011).

Para Gohn (1995), os movimentos sociais foram essenciais para a construção e configuração do Brasil, para a delimitação da cidadania e de espaços (de poder, de disputa, de ocupação) dos agentes e grupos históricos, especialmente do século XX em diante. Assim, olhar 
para um espaço ainda pouco explorado academicamente, como é o movimento estudantil interiorano e de faculdades não públicas, pode contribuir na compreensão da construção das relações e disputas em andamento em localidades onde a vida urbano-industrial estava em configuração, assim como agregar elementos a respeito de como se fundamentou a participação social nessas novas realidades, como se concretizou o predomínio de uma elite local, quais interesses influenciaram os rumos do ensino, a quem ele serviu, entre outros aspectos.

A expansão do ensino teve reflexos em praticamente todo o País (CUNHA; GÓES, 2002) mas, em se tratando do ensino superior, no sul do Brasil, ela ficou em grande parte a cargo de parcerias público-privadas, que deram origem a pequenas faculdades isoladas, conhecidas como comunitárias. Instituições públicas porém de direito privado, as comunitárias deveriam funcionar com orçamento misto: parte da verba seria pública, proveniente de repasses do governo (municipal, estadual, federal), enquanto outra parte seria custeada pelos próprios estudantes através de matrículas e mensalidades.

Chapecó, hoje um município de médio porte, localizado no oeste do estado de Santa Catarina, foi um dos que viu a chegada do ensino superior por intermédio desse modelo, a partir da criação da Fundação Universitária do Desenvolvimento do Oeste (Fundeste) em dezembro de 1971, em lei retroativa a julho de 1970. No ano seguinte, a instituição foi instalada fisicamente e já passou a atuar por meio de seu Centro de Ensino Superior (CES).

Com um processo de colonização efetivamente iniciado em 1917, e marcado pela imigração predominantemente de italianos, entre outros grupos étnicos, e de seus descendentes que habitavam as colônias velhas do Rio Grande do Sul, até aproximadamente 1950, a economia chapecoense foi marcada pela exploração de madeira, erva-mate e pela atividade agropecuária desenvolvida em pequenas propriedades familiares, com cultivo de gêneros diversos, visando à geração de excedente para comercialização (PAIM, 2003, 2006; HASS, 2000; RADIN; VALENTINI; ZARTH, 2016).

Dos anos 1950 em diante, em consonância com transformações que vinham ocorrendo nacionalmente desde 1930, ligadas aos ideais desenvolvimentistas, Chapecó iniciou um processo de modernização pautado na industrialização do campo, que foi também permeado pela diversificação dos interesses da elite política e econômica que desfrutava e disputava o poder local (HASS, 2000).

Nesse cenário, Chapecó, como outras cidades da região, não teve seu desenvolvimento necessariamente marcado pela presença dos povos que ocupavam o território inicialmente. A transição de habitantes, culturas e etnias deixou suas marcas na cidade, tanto geográfica como 
culturalmente. Junto a isso, considerando os traços marcadamente campesinos existentes em Chapecó, assim como em outras localidades do oeste catarinense, questões relacionadas a disputas pela posse de terras tornaram a região um terreno fértil para a presença de movimentos sociais nessa área de luta (PAIM, 2006; POLI, 2008; RADIN; VALENTINI; ZARTH, 2016).

A chegada do Bispo Dom José Gomes, em 1968, ao município de Chapecó também contribuiu para o início de questionamentos e resistências sobre a forma como se davam a organização do desenvolvimento econômico no município - fortemente influenciado pelos interesses da agroindústria - e as relações sociais entre grupos étnicos, socioeconômicos, entre outras questões (POLI, 2008).

A necessidade dos colonos/camponeses em se defenderem mediante as explorações e/ou imposições da agroindústria, de lutar por reconhecimento de direitos e da identidade cabocla e indígena, pela garantia da posse de terras ou de indenizações justas em casos de expropriações, levou à politização de grupos sociais marginalizados. Isso fez com que a industrialização e a urbanização do município, junto à penetração de novas relações capitalistas de produção e consumo, iniciadas com a colonização do município e intensificadas na década de 1970, começassem a sofrer críticas mais duras, ou, ao menos, mais visíveis, transformando o munícipio em um “celeiro de movimentos sociais” (PAIM, 2006; POLI, 2008).

[...] Nessas lutas envolveram-se diferentes setores sociais: religiosos, agricultores, operários, índios, intelectuais. [...] Entre os muitos movimentos surgidos nesse contexto, do Oeste Catarinense, pode-se citar o Movimento dos Trabalhadores Sem Terra, o movimento pela tomada dos sindicatos rurais e a constituição de um sindicalismo combativo no campo, o Movimento das Mulheres Agricultoras, O Movimento de Retomada das Terras pelos índios, o Movimento dos Atingidos pelas Barragens. (PAIM, 2006, p. 134).

Nesse cenário da presença ativa de movimentos sociais diversos, mesmo que em sua maioria, ou totalidade, ligados à questão da terra, os estudantes, especificamente os do ensino superior, também enfrentavam dificuldades. O próprio Centro de Ensino Superior (CES) da Fundeste não viu seu funcionamento iniciado em uma estrutura propriamente pensada para uma instituição de ensino; ele iniciou suas atividades no espaço do antigo seminário católico de Chapecó e, posteriormente, recebeu a estrutura de um hospital psiquiátrico desativado para fixar-se definitivamente.

Tal local, afastado da área urbana mais densamente ocupada no período, apresentava dificuldades de acesso por conta de vias mal sinalizadas, mal conservadas e limitadas linhas de transporte coletivo. Assim, a infraestrutura, a mobilidade urbana, ou mesmo a intermunicipal - 
tendo em vista que o CES/Fundeste atendia pessoas para além do próprio município -, os custos para estudar, quem eram os estudantes, a quem e como o ensino superior trazia benefícios a Chapecó, entre outros aspectos, ainda que possam parecer insignificantes, carregam em si elementos da história da consolidação do ensino superior em Chapecó e, a seu modo, no oeste catarinense.

As análises e reflexões terão por base a realidade que se tem encontrado em uma pesquisa para dissertação de mestrado sobre as lutas políticas dos estudantes do Centro de Ensino Superior (CES) da Fundação Universitária do Desenvolvimento do Oeste (Fundeste) entre 1977 e 1985. Entretanto, o presente artigo terá foco no debate do cenário anterior ao recorte de tal pesquisa, ou seja, no contexto em que se origina a instituição mencionada e que gera as bases para o surgimento de um movimento estudantil local. Assim, o período de interesse para nossa discussão serão as décadas de 1960 e 1970.

Acredita-se que, apesar da especificidade do recorte, as problematizações e constatações possam contribuir para elucidações além dele, seja em generalizações conforme os métodos científicos solicitam, seja em provocações para a observação de contextos parecidos, ou de outras formas.

Assim, teremos como objetivos apresentar a ligação entre a expansão/interiorização do ensino e o projeto desenvolvimentista, problematizar os interesses que influenciaram a implementação do ensino superior no município de Chapecó e apontar a formação de um movimento estudantil no CES/Fundeste junto a algumas de suas demandas e lutas. O trabalho se pautará em pesquisa bibliográfica, a qual se refere a conhecimento já produzidos sobre o período, a localidade e o tema; e em pesquisa documental, neste caso, os encontrados no acervo do DCE do CES/Fundeste sob a guarda do Centro de Memória do Oeste de Santa Catarina (CEOM/Unochapecó).

\section{Industrialização e desenvolvimentismo em Chapecó}

Desde 1930, com a chegada de Getúlio Vargas ao poder, passou a ocorrer no País um esforço em prol da industrialização, com forte intervenção estatal no desenvolvimento econômico focado no modelo de "substituições de importações", que, por sua vez, está alicerçado no processo de industrialização, na defesa de uma política externa independente e do Brasil como potência autônoma (IANNI, 1988).

Por sua vez, sob o slogan "50 anos em 5", no governo de Juscelino Kubitschek (19561961), esse intento industrializante e urbanizador teve seu auge no País, implementando-se um 
programa de desenvolvimento econômico alicerçado na internacionalização dos novos investimentos (IANNI, 1988). Esse projeto está associado à teoria desenvolvimentista surgida no contexto da criação da CEPAL em 1948, que defendia um papel central do Estado Nacional no planejamento de longo prazo, numa articulação entre o econômico e o político e coligando forças estatais, elites empresarias e trabalhadores (IVO, 2014, p. 25).

Em 1964, instalou-se o regime civil-militar, que associou o desenvolvimento à segurança nacional, com discurso para combate à inflação, à corrupção e à subversão. A Doutrina de Segurança Nacional considerou como pernicioso qualquer antagonismo por parte da sociedade, e a repressão foi o instrumento utilizado para garantir a ordem interna no sentido de tornar o País interessante para o capital estrangeiro, o qual, na visão dos militares, poderia acelerar o crescimento da economia interna atrelado ao prosseguimento da industrialização brasileira, iniciado com Vargas e Kubitschek (DUARTE, 2009). O ciclo desenvolvimentista perdurou no Brasil até a década de 1980, quando o modelo passou a dar sinais de desgaste e esgotamento (BIELSCHOWSKY et al., 2011).

Em Santa Catarina, o processo de colonização não ocorreu de modo a integrar as regiões do estado, causando um desenvolvimento fragmentado e desconectado das atividades econômicas. Segundo Gualberto, Cario e Dias (2012, p. 210), “[...] o Estado era recortado por estradas de cargueiros e poucas estradas de rodagem. A desintegração estadual dificultava a comunicação e, portanto, a ligação entre as cidades tanto internamente quanto para outros estados [...]", prejudicando o escoamento da produção e o crescimento econômico.

Nesse contexto, na região de Chapecó, desde o início do processo da "ocupação capitalista" 3 do oeste catarinense, algumas atividades econômicas foram implementadas visando colonizar e explorar o território. Contudo, foi apenas com o ciclo da agricultura familiar, iniciado efetivamente por volta de 1920, após a resolução das disputas que envolveram as questões do contestado, que houve o desenvolvimento de atividades mais permanentes (RADIN; VALENTINI; ZARTH, 2016). Nesse sentido, "A agricultura familiar contribuiu decisivamente para a formação do capital comercial e sua posterior transformação em capital industrial, base do complexo agroindustrial que se desenvolveu na região.” (Ibidem, p. 305).

A fixação ao solo impulsionada pela agricultura trouxe consigo a necessidade de atividades econômicas complementares e a possibilidade de expansão delas, fazendo com que,

\footnotetext{
${ }^{3}$ Utilizamos tal terminologia para diferenciar a ocupação com fins de colonização para exploração econômica da terra, que passa a ocorrer de 1917 em diante, da ocupação anterior que se relaciona aos povos indígenas e de caboclos/posseiros, os quais tinham outra forma de relação de posse e uso da terra.
} 
aos poucos, florescessem o comércio, a indústria e serviços diversos, sobre os quais foram alicerçadas as bases do desenvolvimento socioeconômico e das relações de poder na região (PAIM, 2003; CASSOL, 2007).

Todavia, Chapecó, como outros municípios, sofria com o isolamento em relação à capital do estado e com dificuldades de comunicação com outras localidades dentro e fora de Santa Catarina. Em alguns lugares do estado, as ferrovias eram uma alternativa, porém a opção federal pelo incentivo ao transporte rodoviário em detrimento desse modal levou as ferrovias a serem progressivamente abandonadas, o que contribuía para o quadro das dificuldades na expansão industrial catarinense, comprometendo o escoamento da produção (BIELSCHOWSKY et al., 2011; GUALBERTO; CARIO; DIAS, 2012).

Isso dificultava o crescimento econômico, o fortalecimento das atividades e a acumulação de capital necessária para a realização de investimentos que expandissem a produção para além do mercado local. Nesse sentido, seguindo as políticas nacionais, houve a interferência do Estado no planejamento e desenvolvimento econômico industrial em Santa Catarina. O governo assumiu o discurso desenvolvimentista a partir dos anos 1960 e organizou suas ações juntamente com os setores empresariais e políticos estaduais e municipais,

[...] pois aqui encontra condições objetivas propícias para tal. As condições materiais exigiam novas formas superiores de organização capitalista, estruturada a partir do estado para liberar as forças produtivas que entravavam o processo de acumulação. Em nível local, forma-se, por parte do empresariado, dos políticos e técnicos do governo a consciência de que as questões relativas ao desenvolvimento econômico não poderiam ficar restritas ao governo federal, devendo, portanto, o executivo estadual assumir uma ampla tarefa no que se refere à formulação de metas e execução de programas, ou seja, tarefas no âmbito do planejamento econômico. É assim que a burguesia catarinense passa a reclamar a necessidade da interferência do Estado via planejamento econômico, fazendo com que o aparelho governamental seja re-estruturado para responder aos seus reclames, o que não poderia ser diferente, pois a composição do bloco no poder era de frações da própria classe dominante. (AGUIAR, 2009, p. 151).

Sendo assim, o governo do estado, de 1951 a 1979, implementou uma sequência de planos de desenvolvimento ${ }^{4}$ que visavam à melhoria e expansão da infraestrutura de transporte, energética, produtiva, educacional, sanitária, comunicacional, financeira, etc. (CASSOL, 2007; GOULARTI FILHO, 2010; GUALBERTO; CARIO; DIAS, 2012). Cada plano apresentava ações e investimentos preferenciais em áreas mais específicas mas, de forma geral, todos se

\footnotetext{
${ }^{4}$ De 1951 a 1956, o Plano de Obras e Equipamentos (POE); de 1961 a 1966, o Plano de Metas do Governo de Santa Catarina (PLAMEG I); de 1966 a 1970, o PLAMEG II; de 1971 a 1974, o Projeto Catarinense de Desenvolvimento (PCD); de 1975 a 1979, o Plano de Governo (PG), entre outros.
} 
alinhavam como uma sequência de planejamento na busca do objetivo geral: a promoção do desenvolvimento de Santa Catarina e aproximação dos índices de crescimento estaduais aos nacionais, o que, conforme diferentes análises, foi considerado alcançado.

Foi nesse contexto que se deu o processo de industrialização, urbanização e modernização do município de Chapecó. Diante de dinamizações e de transformações provocadas nos setores produtivos (exploração de madeira e agricultura), nos modos e relações de trabalho (industrialização, legislação trabalhista) e no modo de vida (urbanização), foi possível a ocorrência de uma diversificação de interesses políticos, econômicos e sociais, aliada ao surgimento e penetração de novos agentes nesses campos de disputa (HASS, 2000).

A melhoria nas condições de escoamento da produção, a ampliação do crédito e da energia, a modernização que ocorria no campo (RECHE, 2017), entre outros fatores, possibilitaram ao município de Chapecó, e a parte do oeste do estado, uma industrialização em que a base estava firmada no setor alimentício. Segundo Cassol (2007, p. 13),

Os pioneiros desta incipiente industrialização foram os comerciantes bem sucedidos. Direcionaram seus capitais para a instalação de pequenas indústrias familiares, com reduzido número de operários, direcionando sua produção à indústria alimentícia, com destaque para a industrialização de produtos de origem animal em pequenos frigoríficos.

Deste modo, a instalação de agroindústrias e sua expansão ao longo do tempo foi a grande representação do "espírito desenvolvimentista" focado na industrialização que pairava sobre o País e que estava alcançando o oeste catarinense. Foram cerca de dez frigoríficos criados em três décadas (SILVA; HASS, 2017).

Além disso, houve liberação de mão de obra do campo para as cidades, consequência dos elementos que influenciaram o êxodo rural vivido em diversos pontos do País, o que aumentou decisivamente a atração de pessoas para as cidades. Nesse contexto, Chapecó se consolidou como polo de atração para pessoas tanto do interior do município como de outros próximos, que buscavam melhores condições de vida e emprego na crescente agroindústria ou em outros ramos que se desenvolviam junto às novas demandas naturais tanto do crescimento industrial como do urbano (PAIM, 2003, 2006).

"Com a integração e a consolidação do capital industrial, o desenvolvimento econômico da região oeste catarinense passa a ser conduzido pelas grandes e médias empresas do setor alimentício, como Perdigão, Sadia, Chapecó, Aurora, Seara, dentre outros." (RADIN; VALENTINI; ZARTH, 2016, p. 306). Estas empresas muitas vezes ditaram os interesses e rumos para o município e sua população, seja de forma direta, com a participação de membros 
do seu alto escalão na política, seja de forma indireta, por conta da importância econômica que apresentavam e ainda apresentam (CASSOL, 2007; GOULARTI FILHO, 2010; RECHE, 2017).

O cenário de crescimento demográfico e diversificação de atividades, em que outros setores econômicos também vieram a florescer, trouxe consigo suas próprias demandas, ressaltando-se a necessidade de mão de obra qualificada para atuar em funções mais especializadas (CASSOL, 2007). A política educacional não estava à margem dos processos e planos do desenvolvimentismo catarinense; pelo contrário,

O setor educacional catarinense obteve significativa expansão a partir do PLAMEG. Além de aumentar o número de salas nas escolas já existentes, muitas escolas novas e ginásios foram construídos. No PLAMEG I pretendia-se criar 2.500 salas de aula e elas foram efetivamente construídas. No PLAMEG II somente no primeiro triênio já se tinha a criação de mais 1.806 salas. Os Planos não se limitaram às zonas urbanas, procuraram se fazer presentes nas rurais. Além disso, promoveu treinamentos ao corpo docente que na sua maioria não apresentava a devida qualificação pedagógica. (GUALBERTO; CARIO; DIAS 2012, p. 219).

Letícia Carneiro Aguiar (2009, p. 149), analisando a política educacional catarinense junto ao projeto desenvolvimentista da década de 1960, também reconhece a importância legada ao setor educacional:

Para possibilitar a inserção de Santa Catarina no projeto desenvolvimentista em curso no âmbito federal, desde o governo de Juscelino Kubitscheck (1956-1960), o Estado reservou um importante papel para o setor educacional. Para que a política econômica tivesse êxito, era indispensável promover o ajustamento da educação.

Assim, articulada aos planos de desenvolvimento nacional e estadual, quer como setor estratégico, quer como consequência, a expansão do ensino formal em Chapecó liga-se diretamente às necessidades da elite econômica-empresarial como um requisito para a ampliação do desenvolvimento local. Ainda assim, uma problemática pode ser levantada: serviu a quem a expansão do ensino (básico e superior) no município?

\section{A expansão do ensino em Chapecó e a criação da FUNDESTE}

Com o crescimento da cidade e a concretização de planejamentos estatais, a imagem de progresso e desenvolvimento almejada pelo poder municipal era disseminada, entretanto , questões sociais cada vez mais ganhavam ares de problema devido à falta de infraestrutura, de segurança, de educação, etc., em especial nas áreas periféricas, onde se alocavam as populações menos favorecidas economicamente (RECHE, 2017). 
A cidade cresceu muito, com avenidas largas, espaçosas, bem iluminadas, atribuindo um aspecto bonito, de grandiosidade, que impressiona e seduz seus visitantes. Mas as preocupações em atender a população que aqui chegava e se instalava não produziram os efeitos esperados. Se observarmos os índices de pobreza e marginalização da população que veio para Chapecó, eles são atemorizantes. O crescimento da riqueza e da pobreza se deram proporcionalmente [...] (PAIM, 2003, p. 36).

Assim, fruto de um crescimento urbano além do previsto pelos governantes, a situação de discrepância entre riqueza e pobreza começou a modificar comportamentos e ganhar contornos de problema social. Isso ocorreu especialmente em relação a crianças mais pobres que ficavam sozinhas em casa ou pelas ruas, vez ou outra cometendo pequenos furtos, enquanto seus familiares cumpriam o horário de trabalho nas indústrias ou outros espaços (PAIM, 2003, 2006). Esta circunstância gerou reivindicações para que atitudes fossem tomadas visando evitar o agrupamento de crianças desocupadas e o aumento de ocorrências que envergonhavam um povo que se via como portador de um legado histórico de disposição para o trabalho. Governantes, organizações religiosas, clubes de serviço, entre outros passaram a convocar todos para tomar parte na resolução do problema (PAIM, 2003, 2006).

Para tal, uma das alternativas foi a utilização da educação como ferramenta de ocupação, conscientização e normatização, sendo desenvolvida em processos formais, por instituições educacionais, ou informais, através de propagandas de jornais e rádio que buscam incutir valores e normas ao imaginário social (PAIM, 2003, 2006). Neste sentido, seguiam as orientações da política educacional nacional que visava garantir as aspirações desenvolvimentistas e morais que os governantes tinham para a Nação no contexto de urbanização e industrialização.

Crises sociais ligadas à insuficiência do sistema educacional, o qual não conseguia suprir as demandas do acelerado crescimento urbano, fizeram parte, de um modo geral, da realidade brasileira dos anos 1960 e 1970. Elas, inclusive, serviram como justificativa para assegurar a intervenção e garantia de influência dos interesses do capitalismo estadunidense no País, camuflado como acordos de cooperação (SKIDMORE, 1988; AGUIAR, 2009).

De 1960 a 1980, a educação em Santa Catarina, especialmente a básica, vinculava-se diretamente às políticas educacionais nacionais, observadas atentamente pelo governo da ditadura militar implantada no referido período (AGUIAR, 2009). Essas políticas, conforme aponta Paim (2014, p. 241), “[...] demarcaram dois movimentos contraditórios e complementares: a expansão do ensino e o controle do que deveria ser ensinado." 
Nesse sentido, os modelos de expansão e as reformas propostas pelos acordos firmados entre o Ministério da Educação e Cultura e a United States Agency for International Development (MEC-USAID), desde 1964, pelo Plano Atcon ${ }^{5}$ (1966) e pelo Relatório Meira Mattos (1968) para o campo educacional, junto à visão utilitarista da educação focada no ensino profissionalizante proposta pelo regime militar, concebiam a educação como um meio para a qualificação de mão de obra que suprisse as necessidades das indústrias que se instalavam ou se expandiam no País e das novas áreas de prestação de serviço, ou seja, em prol das necessidades do capital (CUNHA; GÓES, 2002; AGUIAR, 2009; FÁVERO, 2006).

A soma das ideias presentes nesses elementos resultou na Reforma Universitária de 1968, a qual objetivava modernizar as estruturas do ensino superior de modo a ter como base o princípio do rendimento e da eficiência, racionalizar o aproveitamento das vagas oferecidas e atender as demandas de um mercado de trabalho cada vez mais complexo no que diz respeito à utilização de mão de obra. Assim, a reforma tinha como horizonte a formação de recursos humanos na quantidade e com a qualificação necessária para atender as condições que levariam ao desenvolvimento do País (FÁVERO, 2006).

Usava-se para isso o pretexto de que, com a profissionalização desde a educação básica e a consequente qualificação da mão de obra representada por grande parte da população, haveria aquecimento da economia, que fomentaria a criação e entrada de novas empresas no País, por consequência gerando empregos, elevando a renda e minimizando problemas socioeconômicos (CUNHA; GÓES, 2002).

Outro ponto levantado como benefício da educação profissionalizante era a ideia de que, com a conclusão do ensino básico qualificando os estudantes como técnicos aptos a atuarem no mercado de trabalho, a procura pelo ensino superior seria reduzida, minimizando o problema da incapacidade de atender toda a demanda existente. Entretanto, tal expectativa não se concretizou, o que contribuiu para a entrada do capital privado nesse ramo de atuação (CUNHA; GÓES, 2002).

Vale destacar que a política educacional do governo militar acabou por favorecer a privatização do ensino superior, pois, além das estratégias para redução de gastos públicos que viam na expansão da iniciativa privada, inclusive sobre a educação, uma alternativa viável, a

\footnotetext{
5 “[...] trata-se de documento que resulta de estudo realizado pelo consultor americano Rudolph Atcon, entre junho e setembro de 1965, a convite da Diretoria do Ensino Superior do MEC, preconizando a implantação de nova estrutura administrativa universitária baseada num modelo cujos princípios básicos deveriam ser o rendimento e a eficiência." (FÁVERO, 2006, p. 31).
} 
parceria militar-empresarial existente na base do golpe de 1964 precisava também atender os interesses dessa classe civil.

Nesse cenário, em Santa Catarina, durante o governo civil-militar, para que fosse possível ao Estado a definição das bases de sua política educacional na perspectiva da política nacional, com vistas a ações de amplo alcance, entre 1966 e 1971, foram firmados dois convênios: um envolvendo o PLAMEG II, a Universidade do Estado de Santa Catarina (UDESC) e o Centro de Estudos e Pesquisas Educacionais (CEPE); e outro envolvendo o Ministério da Educação (MEC), o Instituto Nacional de Estudos Pedagógicos (INEP) e a Organização das Nações Unidas para a Educação, a Ciência e a Cultura (UNESCO) (AGUIAR, 2009).

Vale esclarecer que

[...] os convênios estavam inseridos numa política mais global do governo federal, já que no período de 1964 a 1968 foi firmada uma série de acordos (doze no total), conhecidos como "acordos MEC-USAID". Esses acordos alcançaram todo o sistema educacional, em todos os seus níveis e em todo o país, e envolviam aspectos voltados à re-estruturação administrativa, planejamento e treinamento de pessoal docente e técnico. (AGUIAR, 2009, p. 154-155).

No oeste de Santa Catarina, coube à Secretaria de Estado dos Negócios do Oeste (SNO), criada em 1963 para integrar a região ao restante do Estado, executar os Plameg, juntamente com as Associações dos Municípios (CASSOL, 2007; SILVA; HASS, 2017). Em Chapecó, apesar das obras realizadas durante o mandato do prefeito Sadi de Marco (1966-1969) e também da Secretaria dos Negócios do Oeste no que se refere à construção de escolas e contratação de professores, o déficit de vagas e, especialmente, de profissionais no setor educacional começou a ser amenizado apenas na década de 1980, mantendo parte da população excluída das benesses proporcionadas pela educação formal (PAIM, 2006).

Além disso, a expansão do ensino no oeste do estado, a cargo do governo federal e estadual, se viu limitada aos níveis fundamental e médio, ficando o ensino superior sob a responsabilidade dos grupos municipais; este, por sua vez, se estruturou por meio de fundações educacionais criadas pelo poder público municipal, mas não gerido por ele, sim pelo direito privado. Ou seja, a implementação dessas instituições conhecidas como faculdades comunitárias “[...] não representou uma expansão da educação pública, mas sim de natureza privada [...]" (PAIM, 2014, p. 241), seguindo a política educacional do governo militar que defendia o ensino privatizado. 
Assim, para a criação de uma faculdade, grupos da sociedade civil e política da região oeste se uniram em um movimento comunitário que foi denominado "pró-universidade". Contudo, frisamos que esse movimento não foi exclusividade no município, pois outras localidades no sul do País, assim como Chapecó, distantes das capitais estaduais e de algum modo desamparadas pelos poderes públicos estaduais e federais, também se valeram da estratégia para que o ensino superior se tornasse uma realidade.

O movimento "pró-universidade" de Chapecó agregou parte da população, autoridades e pessoas influentes política e economicamente do próprio município de outros próximos da região, neste caso, os que, na ocasião, faziam parte da Associação dos Municípios do Oeste de Santa Catarina (AMOSC). Ainda que Chapecó fosse a cidade mais populosa e desenvolvida da região, a educação superior também era uma demanda dos municípios menores, os quais viam na instalação de um Centro Superior de Ensino na cidade uma oportunidade de desenvolvimento também para eles e sua população.

Podemos considerar que o movimento "pro-universidade" de Chapecó foi bemsucedido, já que, por meio de assembleia geral, contando com a presença de autoridades e lideranças de 36 municípios, a Fundeste foi constituída oficialmente em 4 de julho de $1970^{6}$ e reconhecida por lei municipal (n. 141), assinada pelo prefeito na ocasião, João Destri, em 6 de dezembro de 1971, retroativa a sua constituição, como instituição pública de direito privado e com gestão comunitária (FUNDESTE, 2010; Fundo DCE-Fundeste, Cx. 03).

Em 21 de fevereiro de 1972, houve a instalação solene do Centro de Ensino Superior da instituição e, no mesmo ano, iniciaram-se as atividades do curso de Pedagogia, o primeiro curso superior implantado em Chapecó (FUNDESTE, 2010). O curso era, sem dúvida, essencial para as necessidades do município, afinal havia um déficit educacional muito significativo por conta do número reduzido de profissionais da área de ensino e de vagas (PAIM, 2006), o que demandava a vinda de profissionais formados em outras regiões do estado ou fora dele para atuar na área.

\footnotetext{
${ }^{6}$ A Fundeste se manteve atuando diretamente na execução das atividades do ensino superior até 1990, quando se uniu a outras fundações universitárias para constituir a Universidade do Oeste de Santa Catarina (Unoesc), a qual assumiu a responsabilidade das ações do ensino superior em Chapecó e em outros munícipios. Ainda assim, a Fundeste, inativa academicamente, continuou ativa como pessoa jurídica, sendo comantenedora da Unoesc até 2001, ano em que foi reativada, transformando-se, em 2002, na Universidade Comunitária da Região de Chapecó (Unochapecó). Atualmente, a Fundeste continua existindo e em atividade, porém novamente com atuação indireta, sendo mantenedora da Unochapecó, de sua Farmácia-Escola e do Instituto Goio-En.
} 
Como forma de balizar melhor o déficit mencionado, a tabela a seguir apresenta alguns dados sobre a situação da rede escolar de Chapecó.

Tabela 1 - Situação da rede escolar no município de Chapecó

\begin{tabular}{ccccccc}
\hline \hline & \multicolumn{3}{c}{ N. DE PROFESSORES } & \multicolumn{3}{c}{ N. DE ALUNOS } \\
\hline ANO & $\mathbf{1 9 7 2}$ & $\mathbf{1 9 7 8}$ & $\mathbf{1 9 9 4}$ & $\mathbf{1 9 7 2}$ & $\mathbf{1 9 7 8}$ & $\mathbf{1 9 9 4}$ \\
\hline Pré-Esc. & - & 3 & - & - & 253 & - \\
\hline $\mathbf{1}^{\mathbf{a} \cdot-\mathbf{8}^{\mathbf{a}}}$ & 124 & 139 & 183 & 10.829 & 15.971 & 29.888 \\
& 2 & 3 & 12 & 896 & 1.522 & 3.404 \\
\hline $\mathbf{2}^{\mathbf{0}} \mathbf{~}$ & 126 & 145 & 195 & 11.725 & 17.746 & 33.292 \\
\hline TOTAL & & & & & & \\
\hline
\end{tabular}

Fonte: Paim (2003, p. 52).

Os dados podem nos levar a imaginar ou questionar a qualidade do ensino, já que o número de alunos supera muitas vezes o de professores, o que pode sugerir, entre outras dificuldades, salas de aula superlotadas. Além disso, os profissionais da Pedagogia têm sua habilitação para a educação infantil ${ }^{7}$ e anos iniciais do ensino fundamental ${ }^{8}$, assim, as disciplinas específicas do currículo dos anos finais do ensino fundamental e do ensino médio, em suas características mais aprofundadas e suas diferenças metodológicas, continuavam defasadas, já que muitos professores não possuíam formação específica.

O crescimento da rede escolar atendeu a necessidade de dar o mínimo de instrução para parte da população chapecoense. Assim, foram atendidas as exigências empresariais de ter mão-de-obra mais instruída, e não mais educada, principalmente se observarmos o percentual de alunos matriculados no primeiro grau em detrimento do segundo grau. (PAIM, 2003, p. 52, grifos nossos).

O contexto de criação e instalação da Fundação Universitária do Desenvolvimento do Oeste (Fundeste) indubitavelmente veio atender reivindicações da população e suas

\footnotetext{
${ }^{7} \mathrm{O}$ que denominamos aqui como "educação infantil" faz referência ao que, no período, era conhecido como "préescola", pois não era considerado parte efetiva do processo educativo até as mudanças ocorridas na Lei de Diretrizes e Bases da Educação (LDB) durante as décadas de 1990 e 2000.

${ }^{8}$ No Brasil, até 1971 , o primeiro estágio da educação correspondia às séries de $1^{\mathrm{a}} \mathrm{a} 4^{\mathrm{a}}$, o que se denominava como ensino primário, enquanto as séries de $5^{\mathrm{a}}$ a $8^{\mathrm{a}}$ eram o ensino ginasial. A etapa seguinte era denominada de ensino colegial e contemplava os três últimos anos da educação básica. Com revisões na Lei de Diretrizes e Bases da Educação (LDB), a partir de 1971, ensino primário e ginásio fundiram-se, dando origem ao ensino de $1^{\circ}$ grau, o colegial passou a ser o $2^{\circ}$ grau e o hoje ensino superior era conhecido como $3^{\circ}$ grau. Em 1996, novas mudanças foram realizadas na LDB: o ensino de $1^{\circ}$ grau foi substituído pelo ensino fundamental, dividido em anos inicias e anos finais, e o colegial passou a ser o ensino médio.
} 
necessidades, contribuindo para a promoção de desenvolvimento socioeconômico e intelectual, mas, em grande parte, também servindo para atender as demandas do empresariado por capacitação de mão de obra, mantendo-a barata, melhor instruída e disciplinada.

Um ponto que merece ser levantado é que, conforme os trabalhos de Elison Paim voltados para a discussão da educação em Chapecó nos sugerem, havia uma carência significativa de vagas na educação básica, influenciada pela escassez tanto de professores quanto de infraestrutura. Nesse sentido, como já mencionado, a implementação do CES/Fundeste, e a escolha pela pedagogia como primeiro curso da instituição, foi sem dúvidas assertiva em relação às necessidades do munícipio e da região.

Nesse contexto, nos anos seguintes, o CES/Fundeste expandiu seu campo de formação, passando a oferecer os cursos de Estudos Sociais, Administração e Ciências Contábeis. Os dois últimos poderiam até dar ferramentas e conhecimentos para que os formados tivessem condições de ministrar algumas aulas em certas áreas da educação básica, entretanto eles não formavam especificamente professores, mas profissionais voltados a atuar em outras áreas do mercado de trabalho, especialmente, em nosso olhar, aquelas que se relacionavam, seja de forma direta, seja de forma indireta, com as necessidades das grandes agroindústrias. Sobre isso, afirma Paim (2003, p. 63):

Como a preocupação dos fundadores da FUNDESTE era formar mão-de-obra especializada para as indústrias e atividades afins, em 1973 começaram a funcionar os cursos de Administração de Empresas e Ciências Contábeis. Os novos cursos passaram a responder às necessidades dos municípios da região.

Dizemos isso, pois, ao olhar novamente para os dados da tabela anterior, em que Paim (2003) apresenta a situação da rede escolar no município de Chapecó comparando crescimento dos números referentes a professores e estudantes, podemos perceber uma grande discrepância: enquanto o número de professores atuando no ensino fundamental - ou $1^{\circ}$ grau - cresceu em 59 (de 124 para 183) e os que atuam no ensino médio - ou $2^{\circ}$ grau - cresceu em 10 (de 2 para 12), lembrando ainda que nessa separação entre $1^{\circ}$ e $2^{\circ}$ grau podemos ter os mesmos professores atuando nos dois níveis, o número de estudantes matriculados no ensino fundamental - ou $1^{\circ}$ grau - cresceu em aproximadamente 19 mil (de 10.829 para 29.888) e os estudantes matriculados no ensino médio - ou $2^{\circ}$ grau - em aproximadamente 2.500 (de 896 para 3.404), todos dados entre os anos de 1972 e 1994.

Deste modo, enquanto o número de estudantes cresceu estrondosamente, o de professores foi discreto, levando a crer que a instituição formava poucos profissionais da 
educação, ou que nem todos seguiram na área ou atuando no município. Além disso, a diferença numérica de estudantes entre os dois níveis do ensino básico sugere um índice de evasão escolar elevado, também fazendo-nos questionar quantos desses estudantes ascendiam até a educação superior oferecida pelo CES/Fundeste de Chapecó. Talvez, mais importante do que quantos seja questionar quem eram os estudantes do CES/Fundeste, quem conseguia o acesso à educação superior em Chapecó, pois, ao considerarmos que as lutas estudantis são desenvolvidas a partir dos ideais dos envolvidos, conhecendo um, também teremos elementos para compreender o outro.

\section{O diretório central dos estudantes do CES/FUNDESTE e as bases para um movimento estudantil}

Fundado em 1973, ano seguinte ao início das atividades do CES/Fundeste, o Diretório Central dos Estudantes da Fundeste inicialmente apresentava-se por meio da sigla DICEF, alguns anos depois passou a identificar-se como DICES e, por fim, no início de 1980, passou a adotar a sigla DCE, em acordo com a prática comum na grande maioria das entidades representativas do nível superior de ensino. Diante disso, para evitar confusões de nomenclatura, adotaremos o uso da sigla DCE para todas as menções a partir daqui.

De todo modo, vale fazer aqui uma primeira problematização no que se refere justamente a essa diferença de siglas. A diferença de denominação em relação ao usual pelos demais Diretórios Centrais dos Estudantes (DCE), que foram assim denominados a partir da Lei n. 4.464, de 9 de novembro de 1964, mais conhecida como Lei Suplicy, pode ser um indício de que, no início da organização da entidade do CES/Fundeste, havia um real isolamento dos estudantes chapecoenses em relação aos quadros dos movimentos estadual e nacional. Essa perspectiva também é favorecida pela noção de que, no ano de criação da entidade representativa dos estudantes da Fundeste, o movimento estudantil brasileiro encontrava-se desarticulado devido ao sistema repressivo instalado nacionalmente.

As grandes entidades estaduais e a UNE estavam em condição de ilegalidade e, mesmo iniciando-se um processo de reestruturação por volta de 1975, sua situação só foi regularizada em 1979. Naquele ano, o Presidente General João Baptista Figueiredo promulgou a Lei n. 6.683, conhecida como Lei da Anistia, que enfraqueceu a Lei Suplicy de Lacerda - Lei n. 4.464/64 - e revogou os Decretos-lei n. 228/67 e n. 477/69, todas relacionadas à regulamentação e proibição da organização e manifestação dos estudantes (SANTANA, 2007). 
Todavia, propomos, a partir da fala de dirigentes estudantis da época, em entrevistas que estão sendo realizadas, que a diferença de nomenclatura se dava intencionalmente, como forma de afastamento do movimento mais amplo, mantendo assim uma postura de oposição/discordância dele ou mesmo de negação. Contudo, vale lembrar que a nascente organização estudantil do CES/Fundeste contava com características e necessidades bastante particulares, para as quais, segundo nosso levantamento preliminar, suas lutas políticas e reivindicações foram direcionadas.

Dada a chegada tardia do ensino superior em Chapecó, faltava formação curricular às pessoas que já desenvolviam atividades práticas nas áreas dos cursos oferecidos pelo CES/Fundeste (Pedagogia, Estudos Sociais, Administração, Ciências Contábeis em nível de graduação e, posteriormente, outros cursos de formação técnica). Assim, por vezes, a instituição atraía pessoas com idade entre 25 e 35 anos, o que era superior à média geral costumeira em instituições onde o ensino superior já era oferecido havia mais tempo, as quais, já inseridas no mercado de trabalho, configuravam-se como uma espécie de demanda reprimida. Desta forma, podemos supor que esses estudantes dispunham de menos tempo para ações de militância nos padrões realizados nas grandes universidades públicas.

Junto a isso, o CES/Fundeste não tinha uma estrutura própria no início de seu funcionamento, alocando-se primeiramente no antigo seminário católico de Chapecó, e depois recebendo a doação da estrutura de um hospital psiquiátrico desativado para que se fixasse definitivamente. Claramente, ainda que não tenhamos a planta de tal estrutura, devido a sua organização para outros fins, ela necessitaria (e necessitou) de diversas adaptações e aprimoramentos no que se refere às salas de aula, banheiros, espaços de socialização e práticas esportivas, entre outras.

Somando-se a isso, o local, naquele momento, era afastado da área urbana habitada do município, o que, por si só, já dificultava o deslocamento dos estudantes. Entretanto, as vias de acesso também eram mal sinalizadas, mal iluminadas, malconservadas e não dispunham de qualquer calçamento. $\mathrm{O}$ transporte coletivo era outro ponto crítico, pois havia poucas linhas, e em horários bastante específicos, para atender as demandas de deslocamento até o CES/Fundeste tanto dentro do município como para além dele.

Assim, podemos dizer que as primeiras lutas que interessaram aos estudantes da instituição e a seu DCE foram em torno da garantia de uma infraestrutura coerente com suas necessidades educacionais, de lazer/socialização e de mobilidade. Contudo, esses elementos não são passíveis de soluções imediatas; eles necessitam de verbas, autorizações 
governamentais e planejamento para serem solucionados, o que fez com que alguns perdurassem nas pautas estudantis por algum tempo, conforme nota-se por meio dos documentos produzidos pela entidade.

Outro ponto possível de ser levantado se relaciona à qualidade do ensino, a quem ele servia e como os estudantes vivenciavam isso, pois devemos lembrar que o governo ditatorial intervinha nas instituições educacionais para garantir o controle ideológico. Na educação básica, isso se dava pela organização e controle dos currículos educacionais, junto a orientações sobre o que ensinar e como fazê-lo. Também houve nomeações de diretores para garantir o alinhamento aos interesses do governo, a exaltação de datas cívicas, etc. Já nas faculdades isso ocorria por orientações de como deveriam ser organizados os cursos e a contratação de docentes, visando ao adestramento dos sujeitos em sua formação profissional, principalmente no caso da formação de professores (CUNHA; GÓES, 2002; PAIM, 2014).

Não era permitido professores tecerem profundas críticas e reproduzirem ideias consideradas subversivas. No caso da Fundeste, segundo Paim (2014, p. 260), "os dirigentes da instituição foram coniventes com os órgãos superiores [...] era observado menos o critério da 'competência' e mais compartilhar das ideias hegemônicas da ditadura", objetivando a defesa do projeto desenvolvimentista defendido pela Doutrina da Segurança Nacional.

A própria ação dos estudantes também foi alvo da repressão, havendo imitação e tentativa de controle sobre a representação estudantil e sobre os temas que eles poderiam tratar. Muitas das instituições de ensino da época incorporaram em seus regimentos e estatutos internos elementos da repressão que incidiram em forma de decretos e leis sobre os estudantes (CUNHA; GÓES, 2002), o que não foi totalmente diferente no CES/Fundeste.

Sutilmente, os artigos 104, 106 e 109 presentes na Secção III do Regimento Unificado do CES/Fundeste (FUNDESTE, [197-?] p. 40, 42-44), a qual trata da representação estudantil, tangenciam elementos que comungavam com as imposições do Governo Militar e da Doutrina de Segurança Nacional.

SECÇÃO III - Da Representação Estudantil.

$[\ldots]$

Artigo 106 - É vedado ao Diretório Central dos Estudantes a participação ou representação em entidades alheias ao CES sob pena de destituição da diretoria. Promover qualquer ação, manifestação ou propaganda de caráter político-partidário, religioso e racial, bem como incitar, promover ou apoiar ausências coletivas aos trabalhos escolares.

$[\ldots]$ 
Artigo 109 - O DCE é suspenso ou dissolvido pela Direção Geral do CES, quando não se organizar ou não funcionar em obediência aos preceitos legais, estatutários e regimentais da FUNDESTE, e do CES e do DCE. (Fundo DCE-Fundeste, cx 03).

Nesse sentido, entre as décadas de 1960 e 1980, a autonomia das universidades foi abalada, em especial a das públicas, o que motivou muitos enfrentamentos e a politização de grupos estudantis em prol da luta por direitos, qualidade de ensino e liberdade de reflexão, elementos que também podem ser percebidos em reivindicações, ou ao menos reclamações, no contexto chapecoense.

Assim, a qualificação dos professores da Fundeste também foi questionada, tanto por seu perfil técnico como pelo político-ideológico.

[...] Segundo depoimentos de egressos, a desqualificação dos formadores da FUNDESTE no período era visível aos olhos de qualquer aluno que tivesse o mínimo criticidade, pois não possuíam nem pós-graduação em nível de especialização, nem eram pesquisadores. Repassavam aos alunos conhecimentos que se pretendiam apolíticos, neutros, distantes da realidade social em que viviam os acadêmicos. Geralmente, os professores convidados para trabalhar na FUNDESTE foram professores da educação básica. (PAIM, 2014, p. 260).

Nesse sentido, mesmo sabendo que a educação e as escolas - de nível básico a superior - possuem historicidade própria, ou seja, se apresentam com formas e objetivos diferentes ao longo do tempo, é preciso ter em mente que, ainda assim, nem sempre as instituições de ensino vão desempenhar suas atividades coerentemente com sua função social de servir os estudantes e a sociedade como desenvolvedora de potenciais e promotora de transformações, mas, pelo contrário, acabam por vezes se colocando a serviço dos interesses do capital, produzindo trabalhadores "disciplinados" - nestes casos, tornando-os submissos e acríticos (MÉSZÁROS, 2008).

Talvez, para um município onde o povo se orgulhava em carregar o "éthos do trabalho" e de honrar a vocação agrícola da região (FLORES; SERPA, 1999), o ensino voltado às necessidades do mercado de trabalho, ou seja, com características técnico-profissionalizantes, fosse realmente o almejado; e, em um contexto de inserção em uma sociedade urbanoindustrial, os estudantes da instituição que tinha uma concepção público-privada realmente buscassem a transformação social por meio das suas ações por melhores condições de estudo para se inserir no mercado de trabalho, sem estarem articulados com as pautas das lutas contra a ditadura militar dos movimentos estudantis nacionais e estaduais. Deste modo, garantir que o ensino superior tivesse condições de manutenção, de crescimento e de aceitação pode ter sido 
a principal luta do movimento estudantil da Fundeste, mas até quando? É o que ainda vamos "investigar".

\section{Considerações finais}

Em acordo com a conjuntura nacional, o desenvolvimentismo implementado em Chapecó entre os anos 1950 e 1970 apresentou resultados concretos no tocante ao fortalecimento do processo de industrialização, crescimento econômico e urbano do município. Entretanto, configurando-se como polo de atração, o município viu esse crescimento superar expectativas, e ganhar contornos de problema social.

Para a agroindústria e outros ramos econômicos, o excedente de mão de obra era conveniente, garantindo o acesso a um exército industrial de reserva que possibilitava a manutenção de lucros. Entretanto, desqualificada, essa mão de obra passou a necessitar de qualificação para atender novas demandas que acompanhavam o crescimento e a modernização das indústrias e serviços.

Deste modo, o desenvolvimentismo chapecoense no contexto da doutrina de segurança nacional do governo civil-militar reservou um lugar estratégico para o campo educacional, articulado com as políticas educacionais nacionais. A expansão do ensino - tanto básico como superior - agiu em duas frentes: uma que buscava suprir as necessidades da elite empresarial, seja por mão de obra qualificada, seja por aprimoramento próprio; e outra que procurava amenizar os problemas sociais gerados pelo rápido crescimento.

No caso do ensino superior, com a criação do CES/Fundeste em 1972, a precariedade da infraestrutura, o atendimento da demanda reprimida (estudantes-trabalhadores que buscavam formação em sua área de atuação) e a cultura do trabalho presente na mentalidade sociocoletiva de Chapecó foram elementos determinantes para garantir o alinhamento dos estudantes aos interesses do capital industrial - ao menos em um período inicial - e para dar a eles um lugar como agentes significativos na consolidação do ensino superior.

Suas pressões, reivindicações e mesmo algumas ações por meio do movimento estudantil criado em 1973 contribuíram para a expansão quantitativa, qualitativa e estrutural do CES/Fundeste e, de certo modo, do ensino superior no município e do próprio município. Além da responsabilidade financeira representada pelas matrículas e mensalidades, a pressão dos estudantes em questões diretamente ligadas a seus interesses, a exemplo da qualidade do ensino e da infraestrutura educacional, da capacitação profissional e da melhoria na mobilidade urbana, também refletia em benefícios para a sociedade. 
Ainda que timidamente, quer por razão das legislações que impediam ou dificultavam grandes mobilizações, quer por sua recente e incipiente organização, inclusive numericamente pequena, ou mesmo por uma visão diferente do que cabia aos estudantes discutir, não atrelando/vinculando suas ações às pautas do movimento estudantil nacional e estadual, houve uma organização que movimentou os estudantes do CES/Fundeste em lutas políticas. E reafirmamos, sim, lutas políticas, pois já o ato em si de escolher, reivindicar, buscar, agir é um ato político.

\section{Referências bibliográficas}

AGUIAR, Letícia Carneiro. A política educacional catarinense no projeto desenvolvimentista modernizador da década de 1960. Revista Brasileira de História da Educação, Maringá, n. 21, p. 145-175, set./dez. 2009.

BIELSCHOWSKY, Ricardo et al. $O$ desenvolvimento econômico brasileiro e a Caixa: palestras. Rio de Janeiro: Centro Internacional Celso Furtado de Políticas para o Desenvolvimento / Caixa Econômica Federal, 2011.

CASSOL, Evaldo. A Secretaria de Estado dos Negócios do Oeste - SNO: as ações do Estado no desenvolvimento do oeste catarinense (1963-1992). Dissertação (Mestrado em História) Universidade de Passo Fundo, Passo Fundo, 2007.

CUNHA, Luiz Antônio; GÓES, Moacyr de. O golpe na educação. Rio de Janeiro: Jorge Zahar, 2002.

DUARTE, Teresinha Maria. O Projeto de desenvolvimento militar e o estado de Goiás. OPSIS, Catalão, v. 9, n. 12, p. 155-169, jan.-jun. 2009.

FÁVERO, Maria de Lourdes de Albuquerque. A Universidade no Brasil: das origens à Reforma Universitária de 1968. Educar, Curitiba: Editora UFPR, n. 28, p. 17-36, 2006.

FLORES, Maria Bernardete Ramos; SERPA, Élio Cantalício. A Hermeneutica do Vazio: fronteira, região e brasilidade na viagem do governador ao oeste de Santa Catarina. Projeto História - Revista do Programa de Estudos Pós-Graduados de História, São Paulo, n. 18, p. 215-235, maio $1999 . \quad$ Disponível em: <https://revistas.pucsp.br/index.php/revph/article/view/10996/8116>. Acesso em: 18 nov. 2017.

FUNDESTE. Quem $\quad$ Somos. 2010.26 Disponível em: <http://www.fundeste.org.br/index.php/quem_somos>. Acesso em: 26 nov. 2018.

GOHN, Maria da Glória. História dos Movimentos e Lutas Sociais: a construção da cidadania dos brasileiros. São Paulo: Loyola, 1995. 
GOULARTI FILHO, Alcides. Formação econômica de Santa Catarina: uma tentativa de síntese. IN: MATTEI, Lauro; LINS, Hoyêdo Nunes. A socioeconomia catarinense: cenários e perspectivas no início do século XXI. Chapecó: Argos, 2010. p. 29-62.

GUALBERTO, Caio Lauth; CARIO, Silvio Antonio Ferraz; DIAS, Taisa. Estado e planejamento: o plano de metas do governo de Santa Catarina (1961 - 1970) - PLAMEG I e II - enquanto instrumento de política desenvolvimentista. R. Eletr. Estrat. Neg., Florianópolis, v. 3, n. 3, p. 199-232set./dez. 2012. Disponível em: <http://www.portaldeperiodicos.unisul.br/index.php/EeN/article/view/1048/1035>. Acesso em: 8 nov. 2018.

HASS, Monica. Os partidos políticos e a elite chapecoense: um estudo de poder local - 19451965. Chapecó: Argos, 2000.

IANNI, Octavio. O colapso do populismo no Brasil. Rio de Janeiro: Civilização Brasileira, 1988.

IVO, Anete B. L. Estado da Arte da Sociologia nos Estudos sobre o Desenvolvimento. In: MONTEIRO NETO, Aristides (Org.). Sociedade, Política e Desenvolvimento. Brasília: Ipea, 2014.

LIMA, Mateus da Fonseca Capssa. O Lugar da Direita na História e na Historiografia do Movimento Estudantil no Rio Grande do Sul. Anais do XXVI Simpósio Nacional de História ANPUH: São Paulo, jul. 2011. Disponível em: <http://www.snh2011.anpuh.org/resources/anais/14/1312939485_ARQUIVO_2011-ANPUHOLugardaDireitanaHistoriaenaHistoriografiadoMovimentoEstudantilnoRioGrandedoSulcomp leto2.pdf>. Acesso em: 27 set. 2018.

MÉSZÁROS, István. A educação para além do capital. 2. ed. São Paulo: Boitempo, 2008.

PAIM, Elison Antonio. Aspectos da constituição histórica da região oeste de Santa Catarina. Saculum Revista de História, João Pessoa, n. 14, p. 121-138, jan./jun. 2006. Disponível em: <http://periodicos.ufpb.br/ojs/index.php/srh/article/view/11346>. Acesso em: 18 nov. 2017.

. Educação: modernização, democratização do acesso e controle pedagógico. In: BRANCHER, Ana; LOHN, Reinaldo Lindolfo (Orgs.). Histórias na Ditadura: Santa Catarina: 1964-1985. Florianópolis: UFSC, 2014. p. 241-270.

Industrialização e Educação. Chapecó: Argos, 2003.

POLI, Odilon. Leituras em Movimentos Sociais. 2. ed. rev. Chapecó: Argos, 2008.

RADIN; José C.; VALENTINI, Delmir J.; ZARTH, Paulo A. (Orgs.). História da Fronteira Sul. Chapecó: UFFS, 2016.

RECHE, Daniella. O estado e a produção do espaço urbano em Chapecó nas décadas de 1970 e 80. In: NASCIMENTO, Ederson; VILLELA, Ana Laura Vianna (Orgs.). Chapecó em foco: textos e contextos sobre o espaço urbano-regional. São Carlos: Pedro \& João, 2017. p. 37-63. 
SANTANA, Flávia de Angelis. Atuação do movimento estudantil no Brasil: 1964 a 1984. Dissertação (Mestrado em História) - Universidade de São Paulo, São Paulo, 2007.

SILVA, Claiton Marcio da; HASS, Monica. "O Oeste Catarinense não pode parar aqui". Política, agroindústria e uma história do ideal de progresso em Chapecó (1950- 1969). Revista Tempo e Argumento, Florianópolis, v. 9, n. 21, p. 338-374, maio/ago. 2017. Disponível em: <http://www.revistas.udesc.br/index.php/tempo/article/view/2175180309212017338/7011>. Acesso em: 16 out. 2018.

SKIDMORE, Thomas. Brasil: de Castelo a Tancredo, 1964-1985. Rio de Janeiro: Paz e Terra, 1988.

\section{Fontes documentais}

Centro de Memória do Oeste de Santa Catarina (CEOM/Unochapecó), Chapecó-SC. Fundo documental DCE-Fundeste, Caixa 03. 